\title{
Visual information processing of numerical inputs*
}

\author{
D. M. LEVINE \\ Bernard Baruch College (CUNY), New York, N.Y. 10010 \\ and

\section{S. WACHSPRESS, P. McGUIRE, and M. S. MAYZNER New York University, Bronx, N.Y. 10453}

The present paper extends current pattern-recognition research to investigate the processing of numerical inputs. The results indicate major differences in the ease of recognition of the various numbers. The recognition curves developed for each number show vastly different rates of recognition growth for increasing on-time. An analysis of the confusion matrix reveals marked asymmetry of many stimulus-response pairs. The difficulty of the numbers remained highly consistent from $S$ to $S$, suggesting that different $S$ s may utilize similar subroutines at varying processing rates.

In two previous studies (Mayzner \& Greenberg, 1971; Mayzner, 1972), a set of overprinting paradigms was investigated in which there were both informational (letters or digits) and noninformational inputs (noise fields).

Mayzner \& Greenberg (1971) utilized paradigms in which the noise field was the symbol \#, a matrix of points that was the complement of the letter presented, or a full $5 \times 7$ matrix of points. Over the range of $10-60-\mathrm{msec}$ total processing time (on plus off time), the effect of noise fields was highly significant. The partitioning of the on and off time had a significant complex effect on performance. There was more forward masking (noise-letter) than backward masking (letter-noise). The presentation of the noise before the letter may cause the processing subroutines to "hang-up" in their search for a match. There were large differences in the processing of various letters, as as well as wide discrepancies in processing ability between various Ss.

Mayzner and Greenberg suggested that just as digital computers have varying cycle times, humans may have different processing times in coding inputs to the visual system. They suggest that the processing of inputs involves the differential continuous application of coding subroutines rather than the integration or interruption of processing.

Mayzner (1972) studied the complete set of alphabetic letters (except $Q$ ) by presenting the letter immediately followed (without off time between inputs) by a masking field that consisted of the intensification of $5 \times 7$ matrix of points. The results of the study indicated very large differences in recognition between letters. The recognition curves of each letter as a function of on-time varied greatly from letter to letter.

*This research was supported by Grant GB 22785 from the National Science Foundation to the last author.
Some letters improved their recognition rapidly as on-time increased, while other letters did not achieve recognition levels substantially above chance until the on-time approached $20 \mathrm{msec}$. Although execution time varies greatly from $S$ to $S$, the ordering of the letters in ease of recognition is highly consistent from $S$ to $S$. There may be complex interactions between the processing subroutines and the set of letters under examination. Simple subroutines may operate ahead of more complex ones. If an input is composed of simple elements, recognition can occur with only a few milliseconds of display time prior to the arrival of the noise field. It is suggested that the noise field interferes with the application of the processing subroutines in a continuous fashion.

In the present study, the letter-noise overprinting paradigm is extended further by examining the processing of the numerical characters $(0,1,2,3,4,5,6$, $7,8,9)$ at several on-times $(4,8,12,16$, and $20 \mathrm{msec})$. By examining these numerical inputs, it may be possible to evaluate more precisely the ability of the visual system to process patterned information.

\section{METHOD \\ Subjects}

Eight graduate students selected at the University Heights campus of New Uouk University, served as Ss. No S used in this study had served in any previous study of this kind.

\section{Apparatus}

The stimuli were presented on a Fairchild cathode ray tube (CRT) display console slaved to a 340 master display driven by a PDP-7 digital computer. A complete description of this hardware system and its associated computer programs (software) may be found in earlier papers (Mayzner, 1968; Mayzner, Tresselt, \& Helfer, 1967a). An ARS-33 Teletype was also interfaced with the computer, and $S$ made his responses to the inputs presented by typing the appropriate keys on the ASR-33 Teletype.

\section{Materials}

The stimulus materials consisted of the presentation of a single numerical digit (0-9) for a variable on time $(4,8,12,16$, or $20 \mathrm{msec}$ ) immediately followed (using a P-24 instantaneous-decay phosphor), with no delay time, by the presentation of a masking noise field. The noise field consisted of 50 randomly selected (by the computer program) points out of a possible 63 points in a $7 \times 9$ grid of points. The points of the noise field remained on for a constant $500 \mathrm{msec}$ before extinction. The points in the noise field were slightly displaced from the corresponding points in the numerical input.

Display luminance was $1 \mathrm{~mL}$ for a steady state display as measured with a Gamma Scientific photometric system (Model $2020 \mathrm{EA})$. $S$ was positioned $2 \mathrm{ft}$ in front of the display console, with individual digit size fixed at $1 \mathrm{in}$. high and $3 / 4 \mathrm{in}$. wide.

\section{Procedure}

A $2 \times 5 \times 10$ mixed ANOVA design was employed (Winer, 1962, pp. 324-328). Factor A (two levels) consisted of the processing ability groups. The $S s$ whose average score was in the top $50 \%$ were placed in the high-ability group. The Ss whose average acore was in the bottom $50 \%$ were placed in the low-ability group. From previous experiments, it is known that 


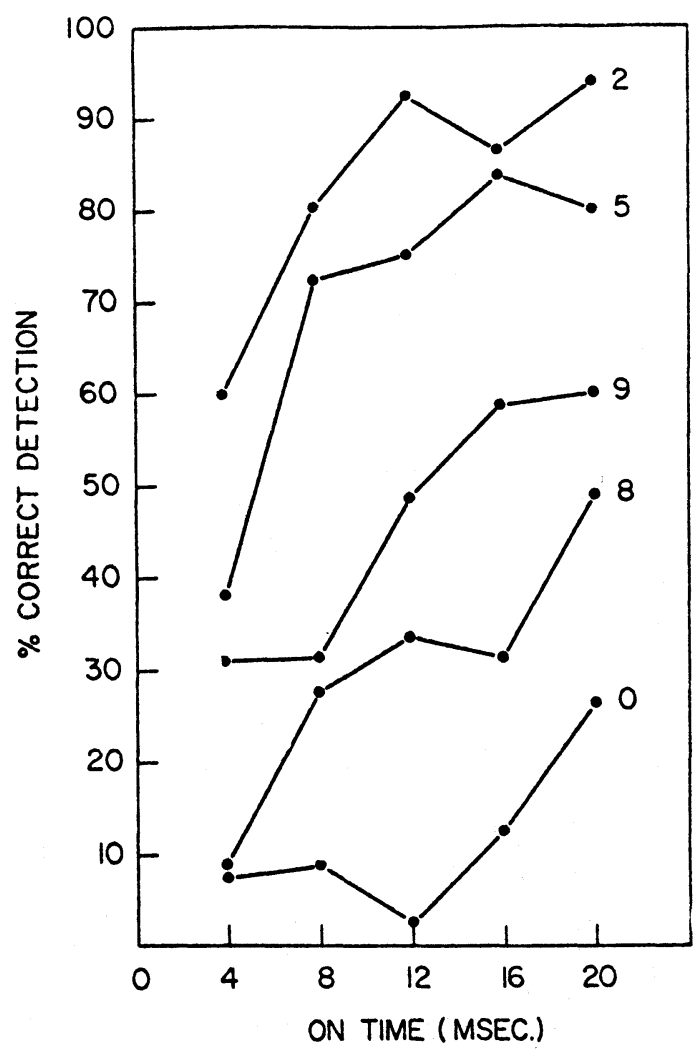

there is a wide disparity in processing ability from $S$ to $S$. The utilization of this factor provides for a more powerful means of testing for the existence of the treatment effects. Factor $B$ (five levels) consisted of the on-time of the numerical input, i.e., 4, 8, 12,16 , or $20 \mathrm{msec}$. Factor C (10 levels) consisted of the different numbers employed, i.e., $0,1,2,3,4,5,6,7,8$, and 9 .

The five levels of Factor B combined with the 10 levels of Factor $\mathrm{C}$ yield 50 treatment combinations. Ten replications per treatment combination were employed, yielding a grand total of 500 test trials per $\mathrm{S}$. These test trials were randomly ordered for each $S$ tested, so that on any given trial, $S$ might receive any number at any given on-time.

At the end of each experiment with each $S$, the computer automatically typed out a printout showing the number of correct responses for each number at each on-time. A paper-tape output indicated the stimulus, response, and on-time for each trial.

\section{RESULTS AND DISCUSSION}

The major results of the study are presented in Fig. 1 and Tables 1 and 2. Figure 1 shows the mean percent correct recall for the eight Ss of the study as a function of the numbers utilized for the five on-times $(4,8,12$, 16 , or $20 \mathrm{msec}$ ). Since percent correct recall scores were employed as the dependent response measure, an inverse sine transformation was applied to the raw scores prior to the ANOVA, as recommended by Edwards (1968, p. 109). The ANOVA showed clearly that Factor $A$ (processing ability) was moderately significant $(\mathrm{F}=10.77, \mathrm{df}=1 / 6, \mathrm{p}>.025)$, while Factors $B$

Fig. 1. Mean percent correct detection for selected numbers. (on-time) and $\mathrm{C}$ (numbers) were highly significant

Table 1

Mean Percent Correct Responses for Numbers and On Times

\begin{tabular}{|c|c|c|c|c|c|c|c|}
\hline \multirow[b]{2}{*}{ Number } & \multicolumn{5}{|c|}{ On Time } & \multirow[b]{2}{*}{ Mean } & \multirow[b]{2}{*}{ Rank } \\
\hline & 4 & 8 & 12 & 16 & 20 & & \\
\hline $\begin{array}{l}0 \\
1 \\
2 \\
3 \\
4 \\
5 \\
6 \\
7 \\
8 \\
9\end{array}$ & $\begin{array}{l}7.5 \\
36.25 \\
60.0 \\
27.5 \\
33.75 \\
38.25 \\
15 \\
51.25 \\
8.75 \\
33.75\end{array}$ & $\begin{array}{l}\quad 8.75 \\
47.5 \\
80.0 \\
50 \\
76.25 \\
72.5 \\
22.5 \\
71.25 \\
27.5 \\
33.75\end{array}$ & \begin{tabular}{l}
\multicolumn{1}{c}{2.5} \\
73.75 \\
92.5 \\
55 \\
76.25 \\
75 \\
41.25 \\
60 \\
33.75 \\
48.75
\end{tabular} & $\begin{array}{l}12.5 \\
92.5 \\
86.25 \\
67.5 \\
91.25 \\
83.75 \\
50 \\
87.5 \\
31.25 \\
56.25\end{array}$ & $\begin{array}{l}26.25 \\
86.25 \\
93.75 \\
77.5 \\
85 \\
80 \\
61.25 \\
67.5 \\
48.75 \\
60\end{array}$ & $\begin{array}{l}11.25 \\
67.25 \\
82.5 \\
58 \\
72.5 \\
70 \\
38 \\
67.5 \\
30 \\
49\end{array}$ & $\begin{array}{r}10 \\
5 \\
1 \\
6 \\
2 \\
3 \\
8 \\
4 \\
9 \\
7\end{array}$ \\
\hline Mean & 31.25 & 49 & 55.875 & 65.75 & 68.625 & 54.1 & \\
\hline
\end{tabular}

Table 2

Confusion Matrix: Number of Incorrect Responses for Each Stimulus

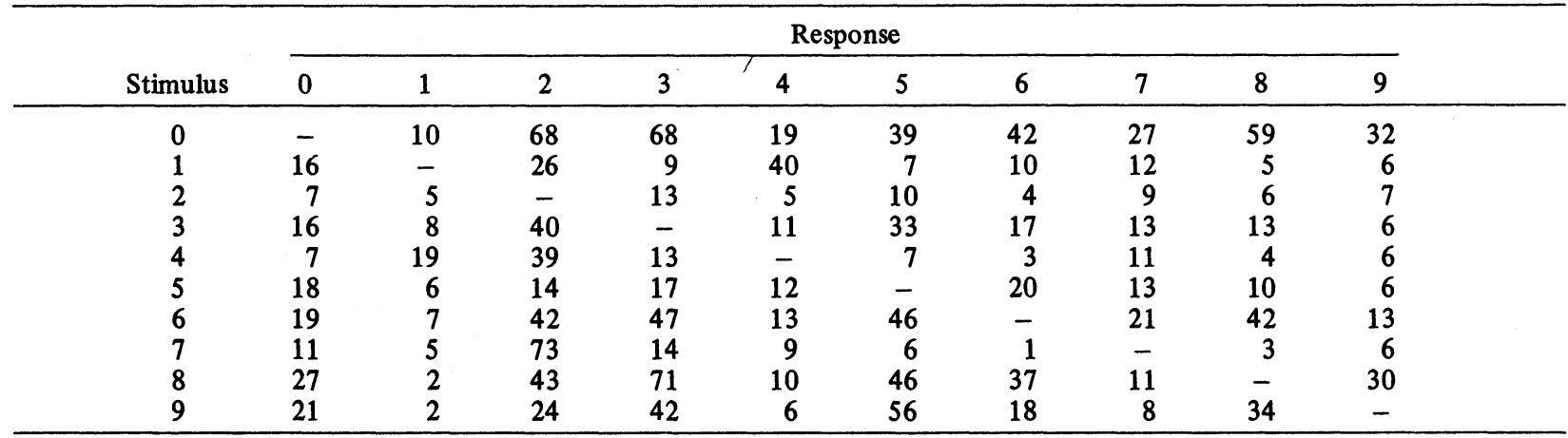


$(F=37.6, \mathrm{df}=4 / 24, \mathrm{p}>.001$, and $F=14.29, \mathrm{df}=9 / 54$, $\mathrm{p}>.001$, respectively). one interaction term, i.e., B by $\mathrm{C}$ was also significant $(F=2.094, \mathrm{df}=36 / 216, \mathrm{p}>.001)$.

These results are clearly consistent with the results indicated in Fig. 1 and Table 1. There were wide disparities in the mean percent recall for the various numbers ranging from $82.5 \%$ for Number 2 to $11.25 \%$ for Number 0. A Tukey-type multiple range test was performed to determine which numbers were different in information processing. The number 0 was far nww difficult to recognize than any other number. There was no major evidence of differences in recognition between the five most easily recognized numbers $(2,4,5,7,1)$, which are all significantly more recognizable than the four numbers that are hardest to recognize $(9,8,6,0)$. These differences between numbers replicate the results of Mayzner (1972) with letters, and provide further evidence that would seem to be difficult to account for by either integration or interruption theory.

The interacting effect of on-time and numbers can be seen by an examination of Table 1 and Fig. 1 . It can be seen clearly that the increase in recognition for increasing on-time is by no means constant for all numbers. The numbers $2,4,5$, and 7 improve their recognition rapidly with increasing on-time. The number 1 needs more processing time to achieve high recognition. The numbers which are most difficult to recognize $(6,8,0)$ are much slower in improving their recognition for increased on-time. For example, the number 8 almost reaches a recognition score of only $50 \%$ after $20 \mathrm{msec}$ on-time, while the number 0 surpasses chance levels only with an on-time of $20 \mathrm{msec}$. These results, by replicating the result of Mayzner (1972), suggest that the pattern recognition subroutines for numbers as well as letters are different for each alphanumeric character.

These pattern-recognition subroutines can be further investigated by analyzing the matrix of errors for each stimulus-response pair provided in Table 2 . This matrix of stimuli and responses is not a symmetric matrix. Two numbers are not confused with each other regardless of stimulus and response. For example, Ss are more apt to respond with 2 when a 7 is presented than to respond with 7 when 2 is shown. Symmetry of confusion appears to be highly lacking for approximately $40 \%$ of the stimulus-response pairs. This suggests that only certain features on the number may be detected in the time available, thereby creating confusions with other numbers having similar components.

Finally, Mayzner (1972) has suggested that different Ss show high degrees of similarity in their orderings of letter-recognition scores. In the current study, the consistency of the ordering of the letters was measured by Kendall's coefficient of concordance (W). For this sample of eight Ss, W was highly significant $\left(0.677 ; \chi^{2}\right.$ $=4 \$ 744, \mathrm{df}=9, \mathrm{p}>.001)$. This $\mathrm{r}+$ ult gives further evidence iv the suggestion that all Ss are using similar processing subroutines at varying processing rates. The difference between Ss may be due to varying execution rates and not be a function of the set of subroutines utilized.

\section{REFERENCES}

Edwards, A. L. Experimental design in psychological research. New York: Holt, Rinehart, \& Winston, 1968.

Ericksen, C. W \& Collins, J. F. Backward masking in vision Psychonomic Science, 1964, 1, 101-102.

Kahneman, D. Methods, findings and theory in studies of visual masking. Psychological Bulletin, 1968, 70, 404-425.

Kinsbourne, M., \& Warrington, E. K. The effect of an after-coming random pattern on the perception of brief visual stimuli. Quarterly Journal of Experimental Psychology, 1962, 14, 223-234.

Mayzner, M. S. The research potential of a computer-based cathode-ray tube display system. Behavior Research Methods \& Instrumentation, 1968, 1, 41-43.

Mayzner, M. S. Visual information processing of alphabetic inputs. Psychonomic Monograph Supplements, 1972, 4, 239-243.

Mayzner, M. S., \& Greenberg, J. Studies in the processing of sequentially presented inputs with overprinting paradigms. Psychonomic Monograph Suppliments, 1971, 4, 73-84.

Mayzner, M. S. \& Tresselt, M. E. Visual information processing with sequential inputs: A general model for sequential blanking, displacement and overprinting phenomena. Annals of the New Y ork Academy of Sciences, 1970, 169, 599-618.

Mayzner, M. S. Tresselt, M. E., \& Helfer, M. S. A research strategy for studying certain effects of very fast sequential inputs on the visual system. Psychonomic Monograph Supplements, 1967a, 2, 73-81.

Mayzner, M. S., Tresselt, M. E., \& Helfer, M. S. A provisional model of visual information processing with sequential inputs. Psychonomic Monograph Supplements, 1967b, 2, 91-108.

Siegel, S. Nonparametric statistics for the behavioral sciences. New York: McGraw-Hill, 1956.

Sperling, G. Successive approximations to a model for short term memory. Acta Psychologica, 1967, 27, 285-292.

Uttal, W. R. Masking of alphabetic character recognition by dynamic visual noise (DVN). Perception \& Psychophysics, 1969, 6, 121-128.

Winer, B. J. Statistical principles in experimental design. New York: McGraw-Hill, 1962.

(Received for publication April 16, 1973.)

\section{Recovery from punishment related to movement and punishment severity}

\author{
JOHN H. HULL \\ Kent State University, Kent, Ohio 44242 \\ and \\ HENRY E. KLUGH \\ Alma College, Alma, Mich. 48801
}

Thirty-two Sprague-Dawley rats were punished for barpressing, using two intensities orthogonal to two durations of shock, until a 5-min nonresponse criterion was reached. Speed of recovery was significantly correlated with proximity to the response manipulandum during the nonresponse criterion period, but independent of the intensity and duration of shock used. Intensity and duration of shock combine to determine severity of punishment. 